so daß das Maximum von November r905 auf Februar 1906 verschoben erscheint.

Würde ich statt der Relativzahlen (nach Wolf) die Intensivzahlen (nach Prof. Epstein) bilden, so würde das Maximum des vorigen Monats vielleicht höher sein, als das des November I 905 , da jetzt Flecke von mehr als $10^{\prime \prime}$ Durchmesser sehr häufig sind.

Dal nach dem Maximum immer noch heftige Aus. brüche stattfinden, die Kurve also in Wellenlinien sinkt, und dementsprechend das Maximum der beobachteten Zahlen vor dem der ausgeglichenen liegt, ist Regel, so z. B.:

1883 Oktober 139.0, ausgegl. I 883 Dezember 92.46 1892 August 176.5, $\quad 1894$ Januar 115.03

Es geht auch aus diesen Zahlen hervor, daß das jetzige Maximum ein schwaches ist.

Jena, I907 März I.

W. Winkler.

\title{
Ephemeride des Kometen 1900 III (Giacobini).
}

Aus unseren wahrscheinlichsten Elementen (vgl. Definitive Bahnbestimmung des Kometen 1900 III, Jurjeff I906) haben wir die folgende Ephemeride für I $^{\text {h }}$ M. Z. Berlin berechnet. Wir fügen ferner zwei weitere Ephemeriden bei, die mit den Annahmen $\eta=\eta^{\prime}-2.5 \varepsilon_{\eta}(x=-0.5)$ und $\eta=\eta^{\prime}+2.5 \varepsilon_{\eta}(x=+0.5)$ gerechnet sind. Störungen sind nicht beriicksichtigt. Die Stellung zur Sonne ist keine günstige, so daß wir, ganz abgesehen von der großen Unsicherheit der Elemente, wenig Hoffnung haben, daß der Komet in der nächsten Zeit aufgefunden wird.

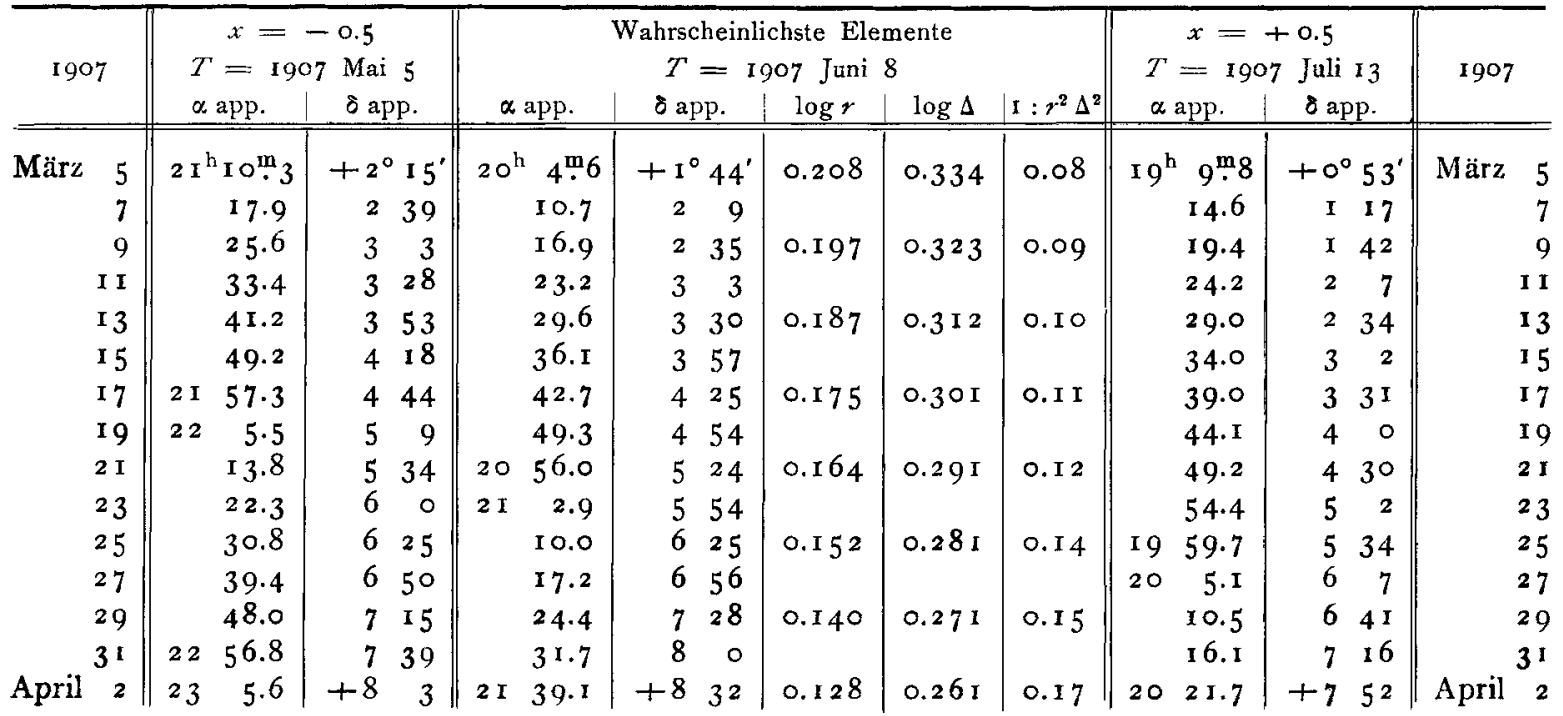

Am I 3. März beträgt die Helligkeit 0.4 der Helligkeit am 15. Februar I go I, an welchem Tage der Komet von Aitken auf Mt. Hamilton zuletzt in der I. Erscheinung beobachtet wurde.

Jurjeff (Dorpat), 1907 Febr. 26.

W. Abold, S. Scharbe.

\section{Ephéméride de la planète (172) Baucis par M. Louis Fabry.}

Les éléments ont été tirés du Berliner Jahrbuch pour r908. Minuit de Paris.

\begin{tabular}{|c|c|c|c|c|}
\hline 1907 & $\alpha 1907.0$ & $\delta 19 \circ 7.0$ & $\log r$ & $\log A$ \\
\hline Avril 9 & $14^{\mathrm{h}} 32^{\mathrm{m}} 43^{\mathrm{s}}$ & $-30^{\circ} \quad 8: 3$ & 0.3914 & 0.1884 \\
\hline I I & $3 \circ 55$ & $30 \quad 11.7$ & 3910 & 1846 \\
\hline 13 & $29 \quad 2$ & $30 \quad 14.1$ & 3906 & 1811 \\
\hline${ }_{5}$ & 273 & $30 \quad$ I 5.6 & 3902 & 1778 \\
\hline I 7 & 25 I & $30 \quad 16.2$ & 3897 & I 748 \\
\hline I 9 & 2256 & $30 \quad 15.8$ & 3893 & 1721 \\
\hline 2 I & $204^{6}$ & 30 I 4.5 & 3889 & 1696 \\
\hline 23 & I 834 & $30 \quad 12.2$ & 3885 & 1674 \\
\hline 25 & 14 I 620 & $-30 \quad 8.9$ & $0.388 \mathrm{I}$ & 0.1656 \\
\hline
\end{tabular}

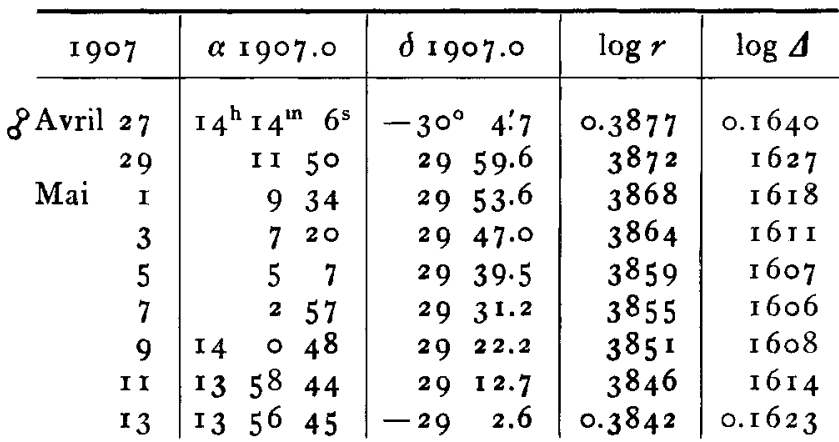

